\title{
GENETIC GAIN OF MILK PRODUCTION IN EGYPTIAN BUFFALO AS AFFECTED BY POPULATION SIZE, NUCLEUS SIZE AND SELECTION INTENSITY IN OPEN NUCLEUS BREEDING SCHEME
}

\author{
S.A. Abdel-Salam ${ }^{1}$, A.A. Nigm, Manal Elsayed ${ }^{2}$, R.R. Sadek ${ }^{1}$ and A.S. \\ Abdel-Aziz ${ }^{1}$ \\ 1- Department of Animal Production, Faculty of Agriculture, Cairo University, \\ Gamaa Street, Giza, 12613, Egypt, 2- Department of Animal Production, Faculty of \\ Agriculture, Ain Shams University, Shubra El-Kheima, Cairo, Egypt
}

\section{SUMMARY}

The objectives of this paper were to investigate the effects of population size, nucleus size, fraction of nucleus dams born in base, proportion of males used as sires, fraction of base sires born in nucleus and fraction of base dams born in nucleus on the expected genetic gain of the open nucleus breeding scheme used for improving milk production of Egyptian buffalo. Simulation technique was used to generate a population of buffaloes with one milk record for each buffalo cow. The average milk yield assumed was $1763 \mathrm{~kg}$. A total number of 848 records of 676 buffalo cows were used to estimate parameters used to simulate populations of different sizes $(10,25$ and 50 thousand). Genetic gain per generation $(G)$ and annual genetic gain $(G / Y)$ were calculated according to James (1977). The genetic gain increased significantly $(P<0.05)$ by increasing population size (z). Increasing nucleus size (p) from 0.01 to 0.05 increased $G$ by $11.8 \%(P<0.05)$. Further increase of $p$ from 0.05 to 0.10 resulted in non-significant effect of only $0.3 \%$. Significant differences among fractions of nucleus dams born in base were observed in $G$ and the same was true for prportion of base sires born in nucleus.

Keywords: Genetic gain, selection intensity, opens nucleus scheme, simulation, Egyptian buffalo

\section{INTRODUCTION}

In Egypt, buffaloes are the favorite dairy animals. They contribute about $60 \%$ to the national milk output. However, its performances, in comparison with standard improved cattle breeds, need improvement. Lack of registered breeding stock represents a serious problem for buffalo breeders. There is a real need to an applicable system capable to produce improved buffalo bulls for insemination and females for replacement. The open nucleus breeding scheme offers a simple procedure for producing and disseminating breeding stock of known value (Cunningham, 1979 and 1987; Hinks, 1974 and 1977; and Jasiorowski, 1991). In developing countries one of the advantages is that nucleus scheme override any lack of infrastructure, such as communication, roads, education and commerce, and concentrate available funds and scientific resources in a few breeding units. Nucleus

Issued by The Egyptian Society of Animal Production 
stocks should be open continuously to introduction of individuals of higher genetic merit from any source. This would help to reduce inbreeding levels.

Several studies indicated the significance of nucleus size in determining the genetic gain (James, 1977; and Dixit and Sadana, 1999). For an economic analysis it would be necessary to introduce costs of establishing and maintaining a nucleus of a given size and costs of female transfer (James, 1977).

Since there is a need for reliable records for genetic evaluation, computer simulation may be a way to generate records for assessing values, and test selection response for different breeding schemes.

This study aims at investigate the effects of population size, nucleus size, fraction of nucleus dams born in base, proportion of males used as sires, fraction of base sires born in nucleus and fraction of base dams born in nucleus on the expected genetic gain of open nucleus breeding scheme on improving milk production of Egyptian buffalo.

\section{MATERIALS AND METHODS}

\section{Generation of the simulated population of buffaloes}

Simulation technique was used to generate a population of buffaloes with one milk record for each buffalo. The average milk yield was assumed $1763 \mathrm{~kg}$. A total number of 848 lactation records of 676 Egyptian buffaloes recorded by Cattle Information System/Egypt (CISE) of Cairo University during the period from 1996 to 2003 were used to estimate various parameters (table 1) which were used to simulate populations of different sizes (table 2).

Populations were generated using Monte Carlo simulation procedure of SAS (1996) with assumed mean (0) and variance (1). Monte Carlo technique was replicated three times to generate three different sizes of buffalo populations: 10000 , 25000 and 50000.

The method of calculating genetic gain depended on estimating the average genetic selection differentials of animals used in nucleus and base. The rate of progress as response to selection is modified by migration of genes between parts of the population with different mean breeding values i.e. from the nucleus to the base and vice versa. Thus, the ultimate genetic gain is given by a weighted average of the genetic selection differentials in nucleus and base, the weights being the gene migration rates from each part of the population to the other. Both additive genetic and residual effects were distributed normally. No fixed effects were simulated. The method was applied for only one generation. The generation interval was assumed to be 5.78 year. It was assumed that all buffalo cows were mated naturally to bulls coming only from the nucleus.

The genotype of animals were simulated by the formula (1) according to (Meuwissen, 1991):

$$
g_{i}=1 / 2 g_{s}+1 / 2 g_{d}+a_{i} \sqrt{0.5 h^{2} \sigma_{p}^{2}}
$$

Where:

$\mathrm{g}_{\mathrm{i}}, \mathrm{g}_{\mathrm{s}}$, and $\mathrm{g}_{\mathrm{d}}$ is the additive genetic value of individual $\mathrm{i}$, its sire and its dam, respectively;

$\mathrm{h}^{2}$ is the heritability in population $\left(\mathrm{h}^{2}=0.25\right)$;

$\sigma_{p}^{2}$ is the phenotypic variance; 
$a_{i}$ is the random number from the distribution $\mathrm{N}(0,1)$,

The lactation of buffalo i was simulated by formula (2) according to (Meuwissen, 1991):

$\mathbf{Y}_{\mathbf{i}}=\boldsymbol{\mu}+\mathbf{g}_{\mathbf{i}}+\mathbf{E}_{\mathbf{i}}$

and

$\mathbf{E}_{\mathrm{i}}=\boldsymbol{\sigma}_{\mathrm{e}} \mathbf{a}_{\mathrm{i}}$

Where:

$Y_{i}$ is the lactation of the $i^{\text {th }}$ buffalo;

$\mu$ is the average milk yield;

$\mathrm{g}_{\mathrm{i}}$ is the additive genetic value of individual $\mathrm{i}$;

$E_{i}$ is the environmental effect of the $i^{\text {th }}$ buffalo;

$\sigma_{\mathrm{e}}$ is the square root of the error variance;

$\mathrm{a}_{\mathrm{i}}$ is the random number from the distribution $\mathrm{N}(0,1)$.

Table 1. The estimates used in generating the simulated populations

\begin{tabular}{lll}
\hline Parameter & Estimate & Reference \\
\hline Average milk yield (MY) & $1763 \mathrm{~kg}$ & CISE, 2003 \\
Phenotypic variance for MY & $316646 \mathrm{~kg}^{2}$ & CISE, 2003 \\
$\begin{array}{l}\text { Phenotypic standard deviation for MY } \\
\text { Average generation interval }\end{array}$ & $563 \mathrm{~kg}$ & CISE, 2003 \\
$\begin{array}{l}\text { No. of females mated per sire per year under } \\
\text { natural insemination }\end{array}$ & $5.78 \mathrm{yr}$ & Mourad, 1990 \\
Heritability & 0.25 & CISE, 2003 \\
& & $\begin{array}{l}\text { Weighted mean of } \\
\text { heritabilities in the }\end{array}$ \\
& & Egyptian literature \\
\hline
\end{tabular}

CISE: Cattle Information System/Egypt

Table 2. Input variables for calculating genetic gain

\begin{tabular}{lcl}
\hline Item Description & Symbol & Value \\
\hline Heritability & $\mathrm{h}^{2}$ & 0.25 \\
Replacement rate & $\mathrm{r}$ & 0.20 \\
Fraction of total population in nucleus & $p$ & $0.01,0.05,0.10$ \\
Fraction of nucleus dams born in base & $x$ & $0.10,0.25,0.50$ \\
Fraction of base dams born in nucleus & $y$ & $0.01,0.05,0.10$ \\
Fraction of nucleus sires born in base & $v$ & 0.00 \\
Fraction of base sires born in nucleus & $w$ & $0.05,0.10,0.20$ \\
Proportion of all males born used as sires & $a$ & $0.05,0.10,0.20$ \\
Proportion of all females born used as dams & $b$ & 0.80 \\
Simulated population size & $z$ & $10000,25000,50000$ \\
\hline
\end{tabular}

Estimation of breeding values for milk yield

Breeding values were estimated using the Derivative - Free Restricted Maximum Likelihood (DF-REML) procedure (Meyer, 1998).

The breeding values of bulls and cows were evaluated by solving model (3)

$\mathbf{Y}_{\mathbf{i j}}=\boldsymbol{\mu}+\mathbf{A}_{\mathbf{i}}+\mathbf{O}_{\mathbf{j}}+\mathbf{e}_{\mathrm{ij}}$

Where:

$Y_{i j}=$ observation of lactation of the $i^{\text {th }}$ buffalo; 
$\mu \quad$ is the overall mean,

$\mathrm{A}_{\mathrm{i}} \quad$ is additive genetic random effect of the individual $\mathrm{i}$,

$\mathrm{O}_{\mathrm{j}} \quad$ is the fixed effect simulated at random after generating the data, $\mathrm{j}=1$ and 2 ,

$\mathrm{e}_{\mathrm{ij}}$ is the random residual effect.

\section{Calculation of expected genetic gain in milk yield}

The expected genetic gain of the open nucleus breeding scheme (ONBS) in the simulated buffalo population is affected by six schematic variables, namely population size $(z)$, nucleus size $(p)$, proportion of nucleus dam replacements transferred from the base $(x)$, proportion of males born used as sires $(a)$, fraction of base sires born in nucleus $(w)$ and fraction of base dams born in nucleus $(y)$.

The parameters assumed for estimating the genetic response of the simulated open nucleus breeding scheme are shown in table 2. Genetic gain per generation and annual genetic gain were calculated using the methodology of James (1977).

Significance of differences among means of genetic gain resulting from applying different input variables was tested using Duncan's Multiple Range Test procedure (SAS, 1996).

\section{RESULTS AND DISCUSSION}

\section{Effect of population size (z) on genetic gain}

Genetic gain increased significantly $(P<0.05)$ by increasing population size $(z)$ (figure 1) due, probably, to the less variability in the small populations. Increasing $z$ from 10 to 25 thousand heads resulted in an increase of $3.1 \%$ in genetic gain. The rate of increase declined to $2.4 \%$ when population size was increased from 25 to 50 thousand heads. However, there were significant differences $(P<0.05)$ among all means. The annual genetic gain $(\mathrm{G} / \mathrm{Y})$ is obtained by dividing genetic gain by the assumed fixed generation interval $(5.78 \mathrm{yr})$.

Change in genetic gain by increasing population size $(z)$ should be taken into consideration, together with available resources and practical situations, when establishing ONBS for improving Egyptian buffalo at the national level.

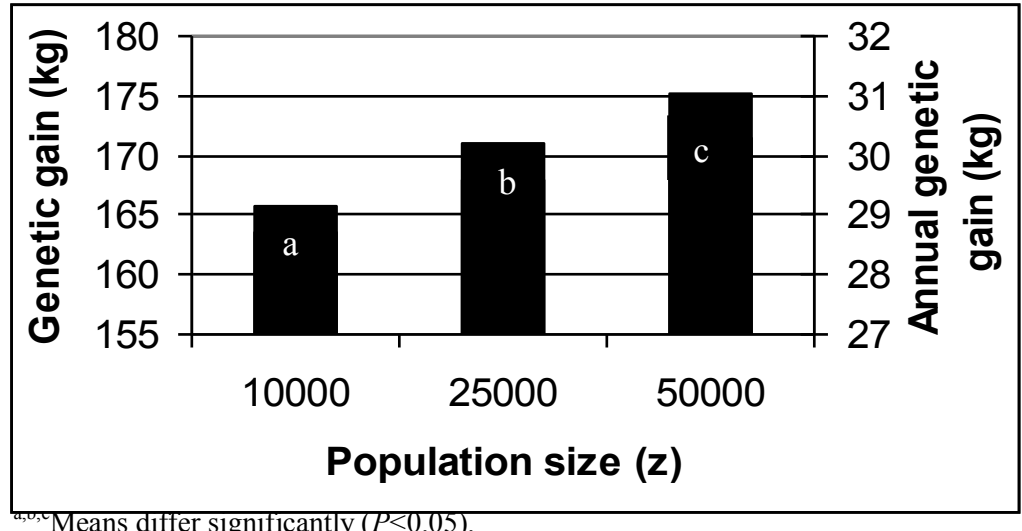

Figure 1. Effect of population size (z) on genetic gain and annual genetic gain 


\section{Effect of nucleus size (p) on genetic gain}

Increasing the nucleus size from 0.01 to 0.05 and 0.10 has resulted in different rates of genetic gain (figure 2). Increasing nucleus size from 0.01 to 0.05 increased expected genetic gain by $11.8 \%(P<0.05)$. Further increase of $p$ from 0.05 to 0.10 resulted in an insignificant effect of only $0.3 \%$ in genetic gain. It seems that, under the assumed population sizes, selecting the best 0.05 of the population to formulate the nucleus is the best option.

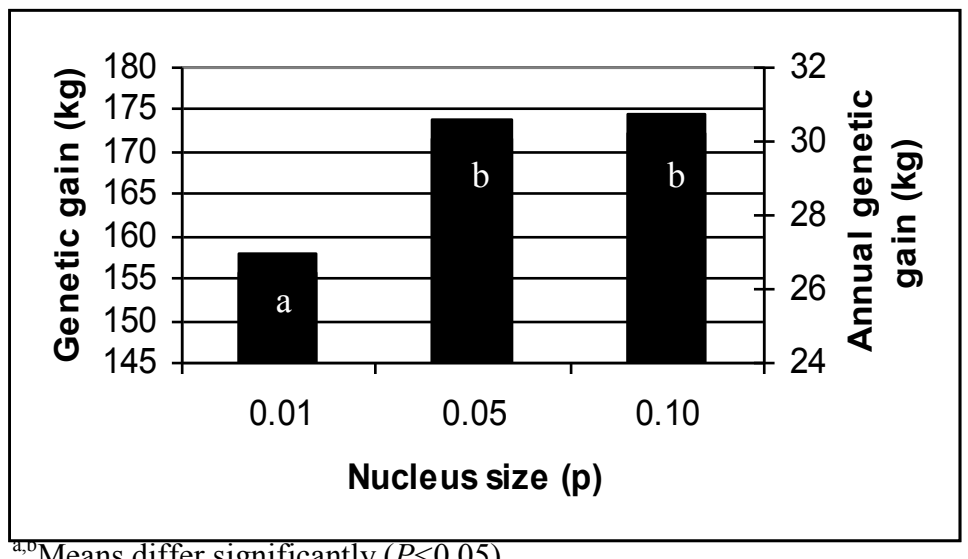

Means differ significantly $(P<0.05)$.

Figure 2. Effect of nucleus size ( $p$ ) on genetic gain and annual genetic gain

\section{Effect of fraction of nucleus dams born in base $(x)$ on genetic gain}

Significant differences were detected $(P<0.05)$ among $x$ classes. Increasing $x$ from 0.10 to 0.25 resulted in an increase of $3.2 \%$ in expected genetic gain (figure 3 ). Further smaller increase of $1.8 \%$ would be achieved by increasing $x$ to 0.50 . However, it should be noted that the fraction of nucleus dams transferred from base is of greater effect in small size populations. The highest genetic gain was achieved when $x=$ 0.50 , which means that half of nucleus replacement females are introduced from the base. This may be required to avoid severe inbreeding in the nucleus. This is the major advantage of open nucleus breeding scheme over closed nucleus scheme. Also, increasing fraction of nucleus dams born in base will permit higher selection intensity in dams born in nucleus.

These results agree with those of James (1977) which showed that the optimal fractions of nucleus dams born in base vary between 0.25 and 0.50 . In sheep and beef cattle, the author reported 0.40 to 0.50 of nucleus-breeding females as recommended fraction to be introduced from the base. 


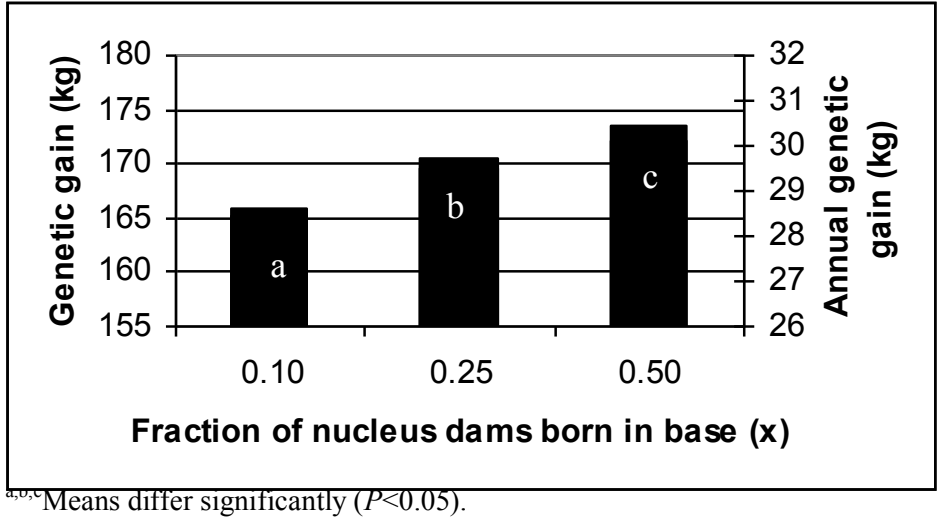

Figure 3. Effect of fraction of nucleus dams born in base $(x)$ on genetic gain and annual genetic gain.

\section{Effect of proportion of males born used as sires (a) on genetic gain}

Significant differences in genetic gain among different proportions of males born and used as sires were detected (figure 4). The decrease of genetic gain with increasing proportion of males selected $(a)$ is logic, since it is due to the less selection intensity in males. Decreasing $a$ from 0.20 to 0.10 resulted in an increase of $1.6 \%$ in genetic gain. The increase was enlarged to $3.3 \%$ when proportion of selected males was decreased from 0.10 to 0.05 .

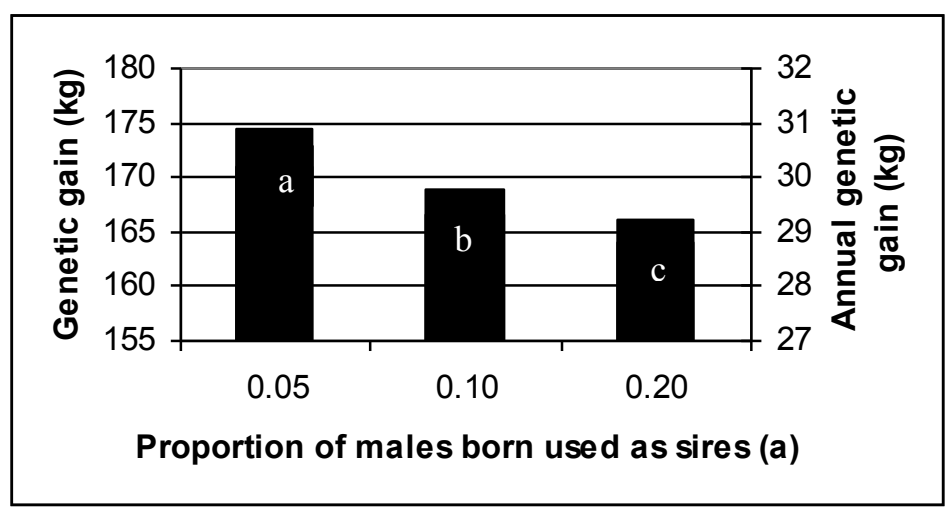

${ }^{\mathrm{a}, \mathrm{b}, \mathrm{c}}$ Means differ significantly $(P<0.05)$.

Figure 4. Effect of proportion of males born used as sires (a) on genetic gain and annual genetic gain 


\section{Effect of fraction of base sires born in nucleus (w) on genetic gain}

Effect of fraction of base sires born in nucleus $(w)$ on genetic gain is shown in figure 5. The genetic gain ranged from 164.7 to $174.2 \mathrm{~kg}$ of milk and the annual genetic gain ranged from 28.5 to $30.1 \mathrm{~kg}$ of milk/year at different levels of $w$. The genetic gain decreased significantly by increasing $w$ from 0.05 to 0.10 or 0.20 due probably to less selection intensity. Differences were significant among 0.05 on one hand and 0.10 and 0.20 on the other hand.

To increase the proportion of base females mated to nucleus sires for a given population, there are two ways: either by increasing the fraction of nucleus sires used in breeding to its maximum practical limit or by increasing the number of females mated to one sire by applying AI techniques for example.

In the first solution, the genetic gain is expected to decrease as the genetic selection differential of nucleus sires decreases. The other solution which is probably more logic will be discussed in a further publication.

These results are in agreement with those reported by James (1977) when setting fraction of sires introduced from nucleus to base. It is, however, of interest to note that the value of $w$ depends on the nucleus size $(p)$ as $w$ increases with any increase in $p$. Also, $w$ depends on the proportion of males born and used as sires $(a)$.

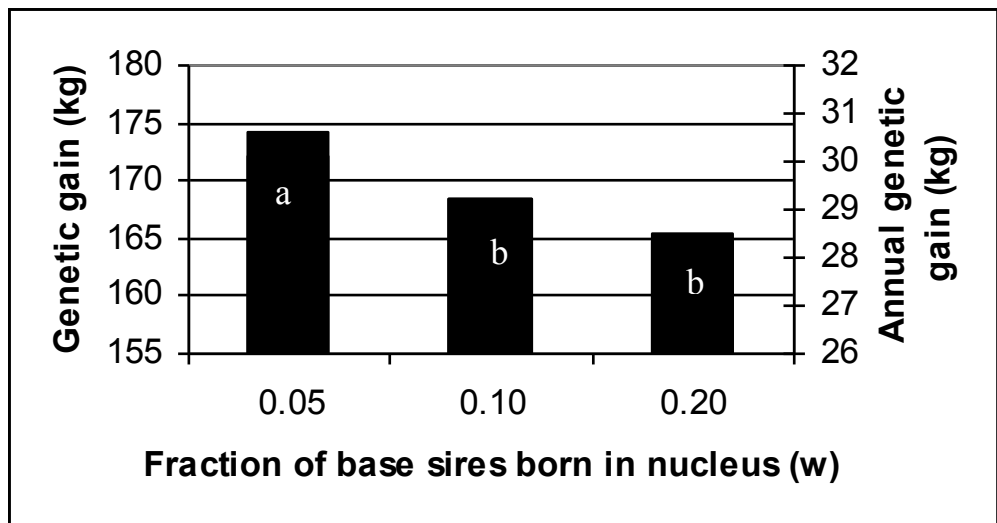

${ }^{\mathbf{a}, \mathbf{b}}$ Means differ significantly $(P<0.05)$.

Figure 5. Effect of fraction of base sires born in nucleus (w) on genetic gain and annual genetic gain

\section{Effect of fraction of base dams born in nucleus (y) on genetic gain}

Effect of fraction of base dams born in nucleus $(y)$ on genetic gain of milk yield is shown in figure 6 . The genetic gain increased with increasing $y$. Significant differences between 0.01 in one side and 0.05 and 0.10 on the other side are shown clearly. Increasing $y$ from 0.01 to 0.05 increased Genetic gain by $4.5 \%$. Further increase of $y$ from 0.05 to 0.10 resulted in an insignificant increase of only $0.3 \%$ in genetic gain.

James (1977) reported that the low value of $y$ is caused by the fact that only a small proportion of base-breeding female needs can be supplied from the nucleus. In 
sheep and cattle then, only a light culling of nucleus-born females would be recommended.

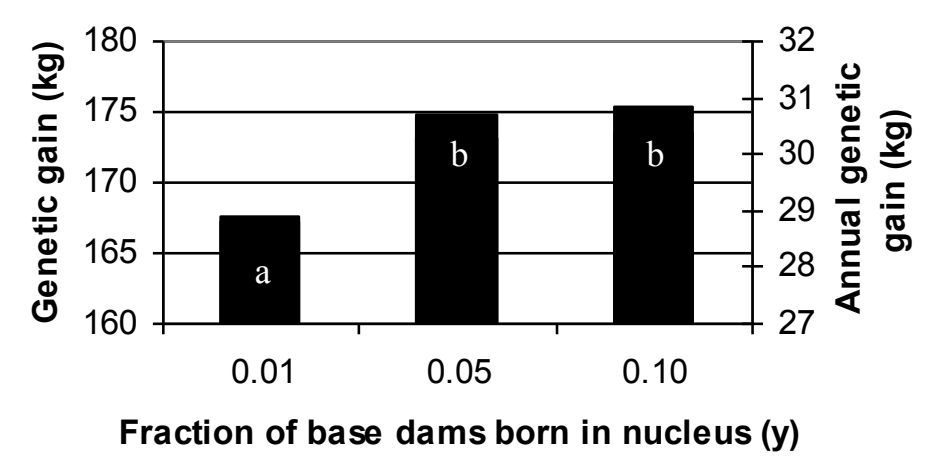

${ }^{\mathrm{a}, \mathrm{b}}$ Means differ significantly $(P<0.05)$.

Figure 6. Effect of fraction of base dams born in nucleus $(y)$ on genetic gain and annual genetic gain

\section{CONCLUSION}

The importance of open nucleus breeding scheme (ONBS) resides in its ability to overcome the lack of national identification and recording systems necessary for breeding programs. The study indicated the possibility of using ONBS in improving milk production of Egyptian buffalo. In the meantime, the study yielded preliminary results about use of ONBS for genetic improvement of milk production in Egyptian buffalo. It draws the attention of animal breeders and decision makers to important practical considerations, to be taken into account, when designing, establishing and exploiting ONBS such as factors affecting the selection intensity (population size, nucleus size, proportion of males selected and fraction of females transferred from the base to the nucleus).

\section{REFERENCES}

CISE, 2003. Periodical report. Cattle Information System/Egypt, Faculty of Agriculture, Cairo University, Egypt.

Cunningham, E.P., 1979. The importance of continuous genetic progress in adapted breeds. Report of the FAO Expert Consultation on Dairy Cattle Breeding in the Humid Tropics, pp. 35-41. FAO, Rome.

Cunningham, E.P., 1987. Crossbreeding Bos Taurus and Bos Indicus for milk production in the tropics. Animal Production and Health Paper 68: 15. FAO, Rome.

Dixit, S.P. and D.K. Sadana, 1999. Response of single trait selection in open nucleus schemes for buffalo breeding. Indian J. Dairy Sci. 52: 17.

Hinks, C.J.M., 1974. The planning and organization of progeny testing with particular reference to numerically small populations and breeds of dairy cattle. 
Zeitschrift fur Tierzuchtung und Zuchtungsbiologie 91: 169. (Cited by Hinks, 1978).

Hinks, C.J.M., 1977. The development of nucleus herd selection programmes in dairy cattle breeding. Zeitschrift fur Tierzuchtung und Zuchtungsbiologie 94: 44. (Cited by Hinks, 1978).

Hinks, C.J.M., 1978. The use of centralized breeding schemes in dairy cattle improvement. Animal breeding Abstract 46: 291.

James, J.W., 1977. Open nucleus breeding systems. Anim. Prod. 24: 287.

Jasiorowski, H.A., 1991. European animal husbandry: a model to adopt or reject by developing countries ?. on the eve of the $3^{\text {rd }}$ millennium, the European challenge for animal production, EAAP Publication 48: 127. (CAB Abst.).

Meuwissen, T.H.E., 1991. The use of increased female reproductive rates in dairy cattle breeding schemes. Anim. Prod. 52: 21.

Meyer, K., 1998. DF-REML (Derivative - Free Restricted Maximum Likelihood) package. Version 3.0 $\alpha .6^{\text {th }}$ World Cong. Genetic. Appl. Livest. Prod., Armidal.

Mourad, K.A., 1990. Buffaloes in Egypt. Proceedings of FAO Workshop on Buffalo Open Nucleus Breeding Schemes (ONBS), Shuman, Bulgaria.

SAS Procedures Guide, 1996. SAS Inst., Inc., Version 6.12., Cary, NC. 


$$
\begin{aligned}
& \text { تأثير حجم العثيرة، حجم النواة وشدة الانتخاب فى نظام النواة المفتوحة على التحسين الوراثى } \\
& \text { لإنتاج اللبن فى الجاموس المصرى } \\
& \text { سامتح عبد الفتاح محمد عبد السلام'، على عطية نجم'، منال السيد '، ربيع رجب صادق' } \\
& \text { و أحمد سعيد عبد العزيز' }
\end{aligned}
$$

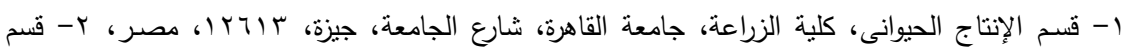

$$
\begin{aligned}
& \text { الإنتاج الحيوانى، كلية الزراعة، جامعة عين شمس، شبرا الخيمة، القاهرة، مصر الإهر } \\
& \text { هدفت الدراسة الى اختبار تأثير عدد من العوامل على نتائج تطبيق نظام النواة المفتوحة لتحسين إنتاج اللبن فى }
\end{aligned}
$$

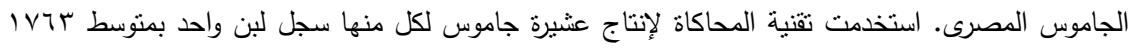

$$
\begin{aligned}
& \text { كجم. استخدم N 1 سجلاً لعدد TVT جاموسة لتقدير المقاييس المستخدمة فى تخليق عثائر مختلفة الحجم }
\end{aligned}
$$

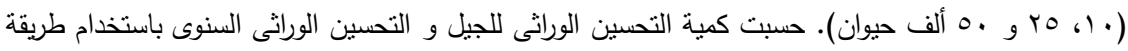

$$
\begin{aligned}
& \text {.James (1977) }
\end{aligned}
$$

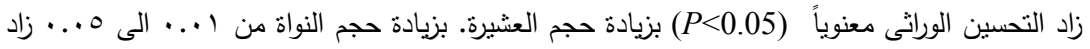

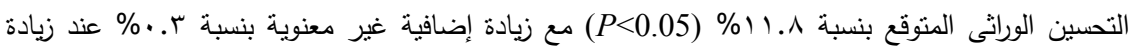

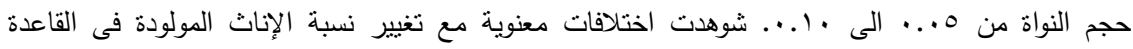

$$
\begin{aligned}
& \text { والمستخدمة فى النواة على التحسين الوراثى المنوقع. }
\end{aligned}
$$

